\title{
Special edition on systems psychodynamics in South African organisations
}

It has been our privilege to take up the role of guest editors of this special edition of the SA Journal of Industrial Psychology. Our sincere appreciation is extended to Prof. Gert Roodt (Editor-in-Chief of SAJIP) and Ms Elize Steenkamp (Title Operations Coordinator at SAJIP) for their support throughout this research endeavour.

This special edition contains the reportage on original research projects on systems psychodynamics as an organisational consultation stance applied in South African organisations. All of these projects used qualitative research designs ranging from conceptual studies to case studies. The content and topics covered a wide variety of organisational phenomena.

This is the first time that such a number and variety of systems psychodynamic research studies have been reported on in the South African context. We hope that the informed scholar will find this special edition a valuable and meaningful resource that facilitates further discourse and research in the stance of systems psychodynamic consultation. We realise that this stance is not broadly known or practised in South African organisations, and we hope that this edition will facilitate increased access for consultants to be trained in and to use this stance in their consulting work.

The research was performed by South African psychologists, consultants and researchers interested in extending the knowledge of consultation and research 'below the surface' (of consciousness and less-conscious processes in the organisational system). Because the teaching of and research in the systems psychodynamic consultancy stance is almost exclusively undertaken at the University of South Africa (UNISA), it makes sense that most of the authors are connected to UNISA. This includes UNISA staff as well as part-time students with full employment in many other organisations in South Africa and in private practice.

In the first article, Deploying culture as a defence against incompetence: The unconscious dynamics of public service work, Mnguni employs social defence theory to explore the manifestations of anxiety within the South African public service sector. Her work contains a conceptual exploration of her personal observations as a reflective citizen. The data revealed the perversion in the deployment of ill-qualified party loyalties to key positions in the public service, and how this serves as a collective defence against the impossible aspects of the task at hand.

In the second article, Improvement interventions: To what extent are they manifestations of social defences?, De Klerk provides his conceptual insights and explanations on how these defences act as drivers for change interventions. The data showed how interventions, although rationally planned, unconsciously contain the organisation's anxiety as a defence against being out of control, boredom and incompetence.

In the next article, Followership's experiences of organisational leadership: A systems psychodynamic perspective, a listening post was used by Greyvenstein and Cilliers, which uncovered the dynamics of the negative experiences of followership towards their leaders. These experiences are influenced by their idealisation of the past, their obsession with race and gender matters and the ever changing identity of the national and organisational leadership context and scenario. Their perception of leadership's non-interest and non-involvement leaves followership feeling hopeless.

Cilliers and May studied The director's roles in containing the Robben Island Diversity Experience (RIDE). This study contributes towards our understanding of how intergroup relations serve as an attack on the role of the director, when studying South African diversity phenomena. The director's authorisation is stressed as an important aspect in keeping to the primary task of these highly dynamic and volatile events.

Humour as defence against the anxiety manifesting in diversity experiences, was studied by Coetzee and Cilliers. The data illustrate how working with the unconscious dynamics of humour in very tense South African and international diversity experiences, leads to meaningful learning and insights into the nature of the manifesting human relationships. An especially meaningful insight is the use of humour as a projection of the fear of owning diverse parts of the self, onto another diverse identity

How to cite this article: Cilliers, F. \& Koortzen, P. (2012). Special edition on systems psychodynamics in South African organisations. SA Journal of Industrial Psychology/SA Tydskrif vir Bedryfsielkunde, 38(2), Art. \#1066, 3 pages. http://dx.doi.org/10.4102/sajip.v38i2.1066

Copyright: @ 2012. The Authors. Licensee: AOSIS OpenJournals. This work is licensed under the Creative Commons Attribution License. 
group and how the exploration of the humorous behaviour facilitates the owning of the projection.

In the sixth article, Executive coaching in diversity from the systems psychodynamic perspective, Motsoaledi and Cilliers applied role analysis to executives in South African government departments. They reported on the difficulty experienced as well as the progress made by the executives in terms of awareness of how gender, race and ethnicity influence their levels of experienced authorisation. It is suggested that individual and organisational role analysis should be used to facilitate diversity awareness towards organisational effectiveness.

A systems psychodynamic description of organisational bullying experiences, describes bullying in terms of the complexity of the behavioural dynamics of all the systemic parts, namely: the bully, the victim, their dyadic relationship as well as the institutionalisation of bullying into the organisational setting. Cilliers reports on how the dynamics of masochism, sadism, narcissism, rivalry and envy keep the bullying relationship going, in order to serve related unconscious agendas in the organisation.

In the next article, The Robben Island diversity experience. An exploration of South African diversity dynamics, Pretorius, Cilliers and May report on the experiences of participants attending this provocative and dynamic annual event. It seems that South African employees are struggling with the crossing of diversity boundaries and, in particular, the building of relationships across race boundaries. The authors suggest that South African organisations are becoming more resilient in their approach to diversity, as is indicated through their willingness to address these matters through Group Relations Training events.

Geldenhuys, Levin and Van Niekerk reported on Risk management as a social defence against anxiety. Their study highlights the necessity of managing risk on the rational level as well as being aware of the unconscious implications during this process. If not, risk management becomes a social defence against the organisation's survival anxiety.

In the tenth article, The impact of silo mentality on team identity: An organisational case study, Cilliers and Greyvenstein report on how organisational silo behaviour influence team identity as an unconscious phenomenon. Organisational consultants are urged not to 'break down' silos, but rather they should attempt to understand the unconscious meaning for the existence of the silo as a symptom of team dynamics, with a much deeper psychological cause.

Working with boundaries in systems psychodynamic consulting, authored by Struwig and Cilliers, produced a set of theoretical assumptions about organisational boundaries and boundary management. From their analysis of two case studies, they developed various hypotheses as a thinking framework for organisational consultants. These focus on balancing the conceptual with the practical towards maintaining a good holding environment and the containment of difficult emotions.

In their article, Exploring the (k)not of relationship between lecturers and management at a historically Black university: The lecturer's perspective, May, Cilliers and Van Deventer described the experiences of the predominantly White lecturers in a historically Black South African university, with the intention of understanding their relationship with the Black university management. The data show how the intergroup relationships, and its power struggle, impact negatively on the performance of both groups.

Henning and Cilliers report on Constructing a systems psychodynamic wellness model, which integrates the principles of systems psychodynamics and positive psychology. The model consists of 39 themes categorised into three levels, namely identity, hope and love. These two fields of psychology has never before been integrated in this manner, and serve as an applicable diagnostic consulting tool for understanding the in-depth aspects of individual, group and organisational wellness.

The article, The systems psychodynamic experiences of first-year master's students in industrial and organisational psychology, contains Cilliers and Harry's rendition of their work with students. Their listening post data revealed how the students' efforts to live up to the expectation of the lecturers, consume their emotional energy to the extent of jeopardising their academic work performance. The authors also gave evidence of how the students' intra group relationships are negatively influenced by their high levels of competitiveness. Recommendations about future tuition at Master's level are offered.

In his article, Leadership coaching experiences of clients with Alexithymia, Cilliers describes the difficulty of clients, with an inability to express feelings, to integrate their learning during role analysis coaching. The data include references to the unconscious transferences of the coach whilst working with such clients. Alternative forms of leadership coaching for clients with Alexithymia are suggested.

In the sixteenth article, Diversity dynamics operating between students, lecturers and management in a historically Black university: The lecturers' perspective, May describes her view on the relationship triad with students and management. The data highlights how race and gender facilitates tremendous amounts of historical and hereand-now anxiety and split. She also formulates interesting hypotheses about how the apartheid struggle skills entrench the Black and White divide.

In their article, Transforming a small business: A learning intervention, Geldenhuys and Cilliers report on the effect of this intervention using a case study design. The study gave convincing evidence of how the learning process assisted the 
organisation to develop its identity from a family business to that of a more formal company, with clearer task and interpersonal boundaries, as well as a more defined sense of authorisation.

Koortzen and Oosthuizen researched the Psychological experiences in South African society before the 2010 FIFA World Cup from the systems psychodynamic and positive psychology perspectives. Colleagues and clients were interviewed. The data revealed the nature of the unconscious anxieties, feelings and conflicts before this international event, such as the fears towards its effect on national identity, as well as positive emotions of excitement and hope for the future.

In the nineteenth article, Geldenhuys focussed on GroupAs-whole as a context for studying individual behaviour: A group diagnostic intervention. Using an action research design, he argues that a group-as-whole stance facilitates a much deeper and richer understanding of the behaviour of the individual group member than, for example, using methods focussing on the individual alone. The advantage lies in the study of the individual's unconscious behaviour in the context of the other and the group. The individual's unconscious splitting, projection and relatedness to others informs the observer about the denied parts of the self.

In the last article, Young, Koortzen and Oosthuizen present their research on, Exploring the meaning of trauma in the South African Police Service: A systems psychodynamic perspective. They report on the intensity of the trauma that police officers are exposed to in their individual experiences, which is exacerbated by the uncontained and unmanageable systemic anxiety. Very little evidence was found of a supportive social network to counter the situation.

\section{Guest Editors}

\section{Frans Cilliers}

Professor, Department of Industrial and Organisational Psychology, University of South Africa, Pretoria, South Africa (cillifvn@unisa.ac.za)

\section{Pieter Koortzen}

Professor, Department of Industrial Psychology and People Management, University of Johannesburg, Johannesburg, South Africa

Saville Consulting, Johannesburg, South Africa (pieter@ savilleconsulting.co.za) 